\title{
Notes
}

\section{Why do North American Red Squirrel, Tamiasciurus hudsonicus, Mothers Relocate Their Young? A Predation-based Hypothesis}

\author{
TRICIA KERR ${ }^{1}$ and SÉBASTIEN DESCAMPS ${ }^{2}$ \\ ${ }^{1}$ McGill University, Department of Natural Resource Sciences, Macdonald Campus, 21,111 Lakeshore Road, Ste-Anne-de- \\ Bellevue, Quebec H9X 3V9 Canada \\ ${ }^{2}$ Département de Biologie, Chimie et Géographie, Université du Québec à Rimouski - Centre d'Études Nordiques, 300 allée des \\ Ursulines, Rimouski, Québec G5L 3A1 Canada; e-mail: sebastien.descamps@uqar.qc.ca
}

Kerr, Tricia, and Sébastien Descamps. 2008. Why do North American Red Squirrels, Tamiasciurus hudsonicus, relocate their young? A predation-based hypothesis. Canadian Field-Naturalist 122(1): 65-66.

Our study reports the first observations consistent with Short-Tailed Weasel predation on juvenile North American Red Squirrels in the nest. Red Squirrel mothers are known to relocate their young to another nest after a disturbance. We suggest that this behaviour might be an efficient strategy that reduces the impact of litter depredation by weasels.

Key Words: North American Red Squirrel, Tamiasciurus hudsonicus, Short-Tailed Weasel, Mustela erminea, nest predation, juvenile survival, juvenile relocation, arboreal foraging, nest defence.

North American Red Squirrels, Tamiasciurus hudsonicus, are known to move their juveniles from one nest to another several times during the period of rearing, especially after nest disturbance (Smith 1968; Long 1993). Although some populations of red squirrels have been intensively studied during the past two decades, this "relocating behaviour" has not received much attention and its adaptive significance remains unknown. At least two explanations can be proposed to explain its existence in an adaptive context. The first one is based on parasitism: survival and growth of juveniles or of the mother herself (Neuhaus 2003) may be enhanced if a female moves her young when the nest becomes too heavily infested by fleas, for example. The second one is based on predation: a female moves her young to decrease predation risk or predation impact on her litter. These two hypotheses are not mutually exclusive and both may play a role in the maintenance of this behaviour. We present here the first observations consistent with predation on juvenile North American Red Squirrels in the nest, which suggests that relocating behaviour by female North American Red Squirrel could enhance their breeding success by decreasing the impact of predation on their litter.

A population of North American Red Squirrels located in southwestern Yukon near Kluane Lake, Canada $\left(61^{\circ} \mathrm{N}, 138^{\circ} \mathrm{W}\right)$, has been studied annually since 1987 (see McAdam et al. 2007 for a detailed description of the study). All female squirrels located in the study area are intensively monitored through live-trapping (Tomahawk traps, Tomahawk Live Trap Company, Tomahawk, Wisconsin), visual observations, and/or radio-telemetry from April to the end of August. Natal nests are located by tracking females near the predicted date of parturition (determined by palpation, and monitoring nipple condition and body mass of the females) and litters are temporarily removed, immediately following parturition and again before emergence, to census offspring. Following our disturbance to nests, mothers have frequently been observed relocating young, one at a time, from nests currently in use to another nest (Kerr and Descamps, personal observations).

On 24 April 2004, we arrived at the natal nest of a recently born squirrel litter in our study grid. Before accessing the nest to census the young we saw a ShortTailed Weasel with a ca. five to ten days old red squirrel in its mouth in front of us ( 2 metres away) bounding slowly through the snow and then disappearing under the snow. After two to three minutes, the weasel reappeared without the juvenile, appeared vigilant for less than a minute, and then disappeared again under the snow. It is likely that the weasel cached the squirrel since Short-Tailed Weasels given the opportunity will kill prey and then store whatever is not immediately consumed (Simms 1979). The weasel seemed to be aware of our presence, which may explain why the weasel did not resurface again. Following this encounter we completed a survey of the litter in the current nest, which contained only one juvenile (ca. 11 days old). We then proceeded to the next natal nest; which was $\sim 100 \mathrm{~m}$ away; we had earlier tracked another mother to it. There, we found a newborn red squirrel (ca. 1 day old) dead on a branch in the natal tree 1-2 m under the nest, where we also found the mother alive. The juvenile's body was flexible, a hind leg had what appeared to be puncture wounds in the thigh, and the base of its skull appeared to have been eaten out. Short-tailed Weasels kill by grasping their prey with their forelegs 
and delivering a fatal bite to the base of their prey's skull (King 1983; King 1989). Weasels usually then eat the brain of a rodent first before feeding on the remainder of their prey's body (King 1989). We believe that these observations strongly support the possibility of nest predation by weasels in our population and that our first encounter was a predation rather than an opportunistic finding of a juvenile squirrel that had fallen from its nest or mother's mouth.

Short-tailed Weasels instinctively kill all live prey in sight (King 1989) and young squirrels in their natal nest would be extremely vulnerable if it was not possible for an adult to chase or lure away a weasel. Defence against a weasel has been observed at our study site, where a Red Squirrel came down from its nest and chased a Short-Tailed Weasel away from its midden (J. T. Humphries, personal communication). This may provide an understanding of the advantages for female red squirrels moving juveniles from one nest to another. Weasels preying on juvenile squirrels after finding their nest may be interrupted by a protective mother and, in accordance with what we observed, may take only one juvenile and then move it to a cache. It is then profitable for the mother to move any remaining juveniles after the weasel leaves and before it returns. This would limit the impact of predation to only one juvenile per attack and contribute to increased survival in juveniles from the litter. If predators fed upon young directly in the nest, this relocating behaviour would not help with the survival of the young and would therefore not be adaptive in the context of predation.

No other predation on a juvenile red squirrel in the nest has been reported to our knowledge; nestling mortality has previously been attributed to exposure, starvation, disease, and maternal mortality (Stuart-Smith and Boutin 1995). According to Krebs et al. (2001, page 207), "when in a nest, squirrels are simply unavailable". Our observation provides evidence that even in a nest squirrels may be available, especially juveniles and it seems probable that weasels are the main predator with the ability to prey upon juveniles while in the nest.

As stated above, parasitism may also play a role in the existence of the relocating behaviour by red squirrel mothers. Further investigation is needed to better understand the adaptive pressures behind the existence and maintenance of such behaviour, but based on our observations and the apparent link between this relocating behaviour and nest disturbance, predation might be important.

\section{Acknowledgments}

We thank Stan Boutin and John Humphries for providing valuable comments on earlier versions of the manuscript, and Rudy Boonstra for encouraging us to submit an account of our observations. Our research, which was the reason we were present to witness these observations, was supported by Stan Boutin, Murray Humphries, and Dominique Berteaux, and was funded by the National Sciences and Engineering Research Council of Canada, Northern Scientific Training Program and the Canada Research Chairs program.

\section{Literature Cited}

King, C. M. 1983. Mustela erminea. Mammalian Species 195: $1-8$

King, C. 1989. The Natural History of Weasels and Stoats. Cornell University Press, New York. 253 pages.

Krebs, C. J., S. Boutin, and R. Boonstra. 2001. Ecosystem dynamics of the boreal forest: the Kluane project. Oxford University Press, Oxford. 511 pages.

Long, C. A. 1993. Bivocal distraction nest-site display in the red squirrel, Tamiasciurus hudsonicus, with comments on outlier nesting and nesting behavior. Canadian FieldNaturalist 107: 104-106.

McAdam, A. G., S. Boutin, A. K. Sykes, and M. M. Humphries. 2007. Life histories of female red squirrels and their contributions to population growth and lifetime fitness. Écoscience 14: 362-369.

Neuhaus, P. 2003. Parasite removal and its impact on litter size and body condition in Columbian ground squirrels (Spermophilus columbianus). Proceedings of the Royal Society of London Series B-Biological Sciences 270: S213-S215.

Simms, D. A. 1979. North American weasels: resource utilization and distribution. Canadian Journal of Zoology 57: 504-520.

Smith, C. C. 1968. The adaptive nature of social organization in the genus of three [sic] squirrels Tamiasciurus. Ecological Monographs 38: 31-63.

Stuart-Smith, A. K., and S. Boutin. 1995. Predation on red squirrels during a snowshoe hare decline. Canadian Journal of Zoology 73: 713-722.

Received 4 May 2006

Accepted 29 January 2009 